\title{
THE POETS INSPIRATION-WATER-THE ELIXIR OF LIFE
}

\author{
Lalitha, $\mathbf{S}$. \\ Department of English, Agni College of Technology, Chennai. \\ E.mail: prof.lalithas@gmail.com
}

\begin{abstract}
Water, the magical substance from which all life springs forth, is essential to the very existence of every life form on earth. Every time our Mother Earth showers her love to all its living beings, it's in the form of water. Water is the only difference between other planets and our mother earth. Humans have cuddled with water forever, all our life revolves around water apart from it being a vital component in our human body. The role of water in the living organism has not changed since life's first creation in salt water billions of years ago. Water is a dominant theme in many of the poetries. The elixir of life, also known as elixir of immortality and sometimes equated with the philosopher's stone, is a mythical potion that, when drunk from a certain cup at a certain time, supposedly grants the drinker eternal life or eternal youth. The elixir of life was also said to be able to create life. It's not without reason that water is called the elixir of life. It has more scientific and natural effects according to the environmental changes. Water when consumed in the right way, not only quenches thirst, but also helps your body detox. A simple day to day routine is to have a full glass of water, and just water without honey or lime or anything, the first thing in the morning, as soon as you get up. The present paper highlights water as an important source of energy in various forms, life giver, an energiser and a source of inspiration to many writers and poets.
\end{abstract}

Keywords: Water, important source of energy, inspiration to many writers and poets, mater and matrix, mother and medium, environmental balance.

Rain, Fountains, Dew, Pools, Ponds, Storm, Thunderstorm, Rivers, Streams, Lakes, Wells, Ditches, Monsoon, Hurricane are all sources of water. Water is a Theme or Metaphor in the Arts and Literature. Visual artists, poets, novelists, composers, playwrights, filmmakers and choreographers have long been inspired by the inherent beauty, movement and sound of water. The list of wellknown paintings, prints, poems, novels, plays, songs, musical compositions and dances that incorporate water as a literal image, as a theme or as a metaphor is immense. Relating to the topic of creative outpourings on water, many poets came across poems that beautifully described how water has no real shape of its own and, therefore, adapts efficiently to its environment. The Water Table by Gross enters a somewhat crowded waterway, and one might be forgiven for doubting that there is much more that can be said. He portrays that no specialist knowledge of or interest in the Severn is required: the river is an inspiration and spiritual inhabitant of these poems, nothing more or less.

Unusually, Gross is not that interested in the metaphorical possibilities of water: this is not a book about grief or loss, nor is his river a method of chronicling social change. Gross, instead, is absorbed in what water actually is its substance, its realness. While water in literature is often a metaphor for what cannot be expressed, in life it has a miraculous physicality all its own and Gross inhabits this completely. It makes for a remarkably solid book despite its fluid foundations. In "Pour", the falling water is "this slick and fluted glitter, slightly arcing, rebranding itself as it falls, as for tangible seconds it's a thin taut string of surface tension that my hand feels, on the handle, as a pulse, a pull, a thing inspace that lives in this world".

"Pascale's poems are as fresh as paint, and make you look all over again at Frida and her brilliant and tragic life. What the Water Gave Me by $\mathrm{n}$ is a triumph of creativity and criticism, of persona and impersonation, of personality and impersonality."

This is how it is at the end me lying in my

While the waters break, my skin glistening with amnion, streaks of starlight.

And the waters keep on breaking as I reverse out of my body. 
Reflections by Douglas R. Hill, a poem on lake describes the beauty of the lake due to its environment.

My favourite spot is by the lake, With forest by the side, 'Cause in the fall with colours bright, Its' beauty we can't hide.

Rain, lovely rain by Sagar Chand explains the beauty of rain and the colourful umbrella used by children and its beauty. As a source of water it gives the ultimate joy also.

Children come to school, On foot, bus or train. They all become wet, When comes the rain. Children open their umbrella, Red, blue or cream. They all shout in joy, Rain you always come in my dream

The poem 'Tsunami' by Brandon Evano portrays the plight of the people during the devastation.

Their souls were in captivity.

So then I wondered, 'Why, oh why, Does God not hear their desperate cry?'

Voices wane into the night,

$\mathrm{Ne}^{\prime}$ er heard in the morning's light,

And in compassion I reached out.

Their land will heal. They will survive.

And to this end, the people strive.

Water is the Hub of Life. Water is its mater and matrix, mother and medium. Water is the most extraordinary substance! Practically all its properties are anomalous, which enabled life to use it as building material for its machinery. Life is water dancing to the tune of solid, says Albert SzentGyorgyi. "It is the omnipresent rush of water which gives the Este Gardens their peculiar character. From the Anio, drawn up the hillside at incalculable cost and labour, a thousand rills gush downward, terrace by terrace, channelling the stone rails of the balusters, leaping from step to step, dripping into mossy conches, flashing in spray from the horns of sea-gods and the jaws of mythical monsters, or forcing themselves in irrepressible overflow down the ivy-matted banks." says Edith Wharton.
The Earth appeared like a precious blue stone set in the blackness of outer space to astronauts for the first time. If inhabitants of other solar systems were to visit this lovely, cool, blue planet of ours, they might just call it "Aqua" rather than "Terra" because of great abundance of its most unique feature - liquid water in streams, rivers, lakes and oceans. Therefore, earth is popularly called as "blue planet". The colour blue denotes the presence of water which covers 71 per cent of our earth's surface. Since water covers 3/4th of our planet, it is readily available, yet water is one of earth's most precious resources.'A river seems a magic thing. A magic, moving, living part of the very earth itself 'says Laura Gilpin.

Tennyson makes the brook narrate its history- the history of its origin, its meandering and uneven journey through forest and hills and open spaces until it joins the 'brimming river'. The Brook originates from a source on the highlands filled with mountain forest cover, where the wild birds of coot and fern are found in plenty. Its rushing waters touch all the ferns that grow on its banks till it reaches the open valley. In its initial rushing journey, the brook passes through the slopes of thirty hills and flows beneath more than four dozen bridges. Then it touches twenty different villages before reaching a little town.

I come from haunts of coot and fern, I make a sudden sally

And sparkle out among the fern,

To bicker down a valley.......

And out again I curve and flow

To join the brimming river,

For men may come and men may go, But I go on forever.

Before joining the main river, the brook passes by Phillip's farm. As it comes rushing down the hills, its waters produces different musical notes as it dashes against the stony pebbles. The brook makes its presence felt when it passes through the different fields of uncultivated lands and many front lying promontory lands where the weeping willows grow. It winds about with immense power and its cool pleasant waters bring all kinds of fresh water fish to a lively activity. Each morning when the sun rises, the rays and the beams hit the waters and brightly reflect the shiny dance of the active movement of the brook on the sandy banks. When evening sets in and total darkness covers the surroundings of the countryside, the flow of the brook continues to murmur under the light of the moon and stars. The effect of the brook on the shores 
in the daytime is as much as in the night. Tennyson significantly relates the brook to human life to the sad reflection that man's life is impermanent compared with the relative permanence of a river. The brook flows down along hills. Sometimes, it also glides between long and narrow hill ranges, called ridges. Thorpes refer to small villages or hamlets. Between two small towns, the brook passes several Thorpe's and a large number of bridges. The numbers used in this line such as 'thirty', 'twenty', 'half a hundred' should not be taken in the literal sense. These numbers are used to give the impression of 'several' or 'many' and to maintain the rhythm of the poem.

Robert Creeley in his poem on rain explains his mental tense being reduced due to the rain

"My sweetness is to wake in the night after days of dry heat, hearing the rain".

Water is the formless potential out of which creation emerged. It is the ocean of unconsciousness enveloping the islands of consciousness. Water bathes us at birth and again at death, and in between it washes away sin. It is by turns the elixir of life or the renewing rain or the devastating flood says Scott Russell Sanders. A river flows from an upland source. Here the velocity of water is faster than downstream because the river's gradient is steep. Near a river's source the valley has a narrow floor and steep sides' .The middle course of the river has a wider floor and the sides of the valley are more gently sloping. The velocity is slower than the upper stage. However, the channel is wider as the amount of water flowing in it increases as other streams and rivers join it. The lower course of the river is very gentle sloping, almost flat. The channel is usually at its widest and deepest here because the amount of water flowing within the river is at its greatest. Rivers erode in four ways: Abrasion or corrosion which is, when large pieces of bed load material wear away the river banks and bed. Attrition,when the bed load itself is eroded when sediment particles knock against the bed or each other and break, becoming more rounded and smaller, Hydraulic Action, the force of water erodes softer rock and Solution or corrosion ,when acidic water erodes rock. Floods can bring both advantages and disadvantages to an area. Floods can deposit rich, fertile alluvium on agricultural areas. Also, flood water can replenish irrigation channels. On the other hand floods can destroy food supplies, homes and transport infrastructures. The poem Waterfalls an acrostic poem by Molly is a classic creation which is set to the tune of the waterfall.
Whooshing, pushing, gushing over rocks

Attacking everything in sight

Thrashing, bashing, crushing rocks and things like

that

Error, terror, hear the power

Recking, decking, pecking in and out of rocks

Faster, crashier, bashier all around the place

Arting, darting, carting all the rocks around

Looking, cooking, booking in and out like a meander

Lushing, sushing, mushing, every-where.

Three quarters of the earth's surface is covered by water. The ocean conceals billions of creatures interacting in ways that we will never fully understand. Much of the ocean is mysterious. We cruise along on boats on the ocean's surface, and sit on beaches watching the ocean's surf meet the land. One of the great things about the ocean is that we cannot build on it. It will remain a vast open space perfect for contemplation. In a poem Sea Poem, A Day At Sea by Melissa Roberson, the poet beautifies the qualities of the ocean and the sea waves as a shelter to the fishes and the sea shells. The greeting of the ocean waves over the sand is a pleasant sign expressed by the poet

As the ocean waves at me,

And the sand greets the sea,

The fish swim free,

And shells wash up by me.

The sand squishes suddenly,

Between my shoeless toes.

Then the tide flows over ..........

The poem the Ocean by Robert Frost beautifully explains the quality of the ocean and how a poem can stir all of the senses, and the subject matter of a poem can range from being funny to being sad. The sentiments in the words by Robert Frost finds even more effective.

The shattered water made a misty din. Great waves looked over others coming in, And thought of doing something to the shore That water never did to land before.

A poem can stir all of the senses, and the subject matter of a poem can range from being funny to being sad. Children love to play in water. Famous nursery rhymes have inspired the children to play that water never did to land before. Water gives the total joy and enthusiasm to the children.

Jack and Jill

Went up the hill,

To fetch a pail of water;

Jack fell down, 
And broke his crown, And Jill came tumbling after.

Rain, rain, go away, Come again another day, Little Johnny wants to play.

Rain, rain, go to Spain,

The rhymes till date are a source of inspiration and joy to the children for joy and play. Children love to play in rain water. Generally people love waterfalls or the cascade, beach waters, etc. Water as a source of living makes man healthier. There is an environmental balance because of water. Imbalance of water will lead to the greenhouse effect. Disproportionate density of flora and fauna leads to global warming.

The ability of water to form of sipping water after reciting Vedic mantras that is believed to have therapeutic effect on its practitioner. Chanting creates a "memory structure" in water, somewhat like homoeopathic medicine where high potencies don't have original medicine in it but the "memory structure" of the medicine persists in water. The poem given below byMeish Goldish explores the availability of water as a source of living for all the living beings. It explores how water is a source of energy to all the living beings on earth for their sustenance.

Water, water everywhere, water all around, Water in the ocean, water in the ground. Water in a river, water in a creek, Water in a faucet with a drip-drip leak! Water in a fountain, water in a lake, Water on a flower, as day begins to break. Water from a waterfall, rushing down from high, Water from a dark cloud, raining from the sky. Water boiling hot, water frozen ice, Water in a blue lagoon, clean and clear and nice. Water at a fire, gushing through a hose, Water in a garden, so every flower grows.
Water for the animals swimming in the sea, Water, water everywhere for you and for me!

Water is a renewable natural resource and public good. But the ownership right on land bestows a private character on water. However, most rivers, ponds, lakes and aquifers are common property. Therefore, water rights are not clearly defined and the right to using the resources is not protected. Hence, excluding others from using water is not possible and the results are competition, overextraction and conflict. However, cooperation has a greater role in achieving social harmony in water allocation and increasing human welfare. "If there is magic on this planet, it is contained in water." says Loren Eisley

Living water is the elixir that facilitates creative mind. Underground water is one of the key earth resources. Unfortunately, this resource has been depleting at an alarming rate. It is a matter of great concern. Water is indispensable for not only human beings, but also for animals and environment as well. Due to increasing use of water for various domestic, commercial and agricultural purposes, water table of all over the world is going down at an alarming rate. Protecting water resources is vital for the conservation of all species which are extincting very fast. The oceans are the planet's last great living wilderness, man's only remaining frontier on Earth, and perhaps his last chance to prove himself a rational species.

\section{REFERENCES}

Alexander, J.H. 1987. Reading Wordsworth. London: Routledge and Kegan Paul.

Bacak, Matt.Reader's, 2009. Guide to William Wordsworth. New Delhi: Centrum.

Hill, John Spencer, 1977. The Romantic Imagination, A Selection of Critical Essays, The Macmillan Press Limited, ISBN - 0333212347 (hc), 033 212355 (pbk). 